\title{
㭳 \\ Engineering education: an integrated problem-solving framework for discipline-specific professional development in mining engineering
}

\author{
by G. Haupt and R.C.W. Webber-Youngman
}

\section{Synopsis}

This article is based on the premise that the purpose of engineering education, in general, is to deliver engineering practitioners who are intellectually capable of identifying, structuring, and solving complex problems, and that solving engineering problems is systemic. The solutions to problems are viewed as objects, tools, processes, and systems. The purpose of this article is, however, to specifically explore some of the aspects of the intangible world of mining engineering from a generic problem-solving perspective, which would also be applicable to any other engineering discipline. This is done by focusing on higher order intellectual processes when processing information in the problemstructuring and problem-solving space. As such, this article builds on a previous study in which the intangible world of the mining engineer was identified as worth investing in. We begin by briefly reviewing the complexity of the mining engineering problem-solving space and the background and role of a generic cognitive approach to problem solving in the mining engineering curriculum at the University of Pretoria (UP). Several dimensions of extended cognitive processing are then detailed, explaining why the early phases of problem solving are difficult to learn, and more difficult still to teach. An outline is given of the classification of types of mining engineering problems, and its determinant role in the dynamics of information processing. Conceiving, designing, implementing, and operating (CDIO) as an overarching engineering methodology is discussed, together with the subsequent mapping of cognitive phases onto CDIO stages. Finally, we pose an open research question that seems important to answer in order to identify the best pedagogical practices for improving problem-solving capabilities not only in mining engineering but also in other engineering disciplines.

Keywords

extended cognition, information processing, problem solving, systems thinking. mining engineering education therefore requires mastering of the necessary knowledge, and the teaching and learning of skills in ill-structured, non-routine, real-world problem-solving contexts (Jonassen, Strobel, and Lee, 2006).

In the mining environment, these problems vary from well-structured repair-type problems (including repair and replacement of faulty equipment), to semi- and entirely ill-structured problems. The latter can include the upgrading of safety infrastructure, optimizing the application and use of existing mining and mining-related equipment, processes, systems and procedures, as well as the design of innovative tools and systems to operate effectively and adapt to changing physical mining conditions. In all of this, occupational health and safety $(\mathrm{OH} \& \mathrm{~S})$-related hazards and risks need to be considered and addressed so as to ensure a safe, healthy, productive, and profitable working environment.

The certified level of engineering education outcome and level of experience of the mining engineering practitioner (ECSA, 2015) together determine the nature and complexity of the problems a particular practitioner might be entrusted to solve. For this reason, when mining engineering learners at the University of Pretoria (UP) embark on their final year real-world mining projects, they are usually given relatively well-structured problems to solve. This, however, does not preclude introducing them to semi- and ill-structured problems as part of a larger research project or team effort. Establishing a sound problemsolving development process will serve them well in dealing with the semi- and illstructured problems that they will encounter in their future careers.

One of the reasons for the difficulties in mining engineering education is that the mining environment is complex. Complexity

\footnotetext{
* University of Pretoria, South Africa.

(c) The Southern African Institute of Mining and Metallurgy, 2018. ISSN 2225-6253. Paper received Jan. 2017; revised paper received June 2017.
} 


\section{Engineering education: an integrated problem-solving framework}

here refers to mining engineering being embedded in a country's social, technical, and economic systems (van der Merwe, 2011). In this environment, mining and other engineering practitioners are often faced with having to choose the best approach to solving the various types of problems encountered in a mining environment (Kluge and Malan, 2011). These problems are all context-bound, and require sensitivity to the type of information, methodologies, and tools required to make appropriate decisions. A sustained effort is needed to constantly improve $\mathrm{OH} \& \mathrm{~S}$ at mines, and continued research is necessary on changing physical mining conditions to secure revenue from the sale of coal, platinum, gold, and other minerals. In addition, there seems to be a need to streamline the transfer of knowledge to future mining engineering practitioners (van der Merwe, 2011). The complexity of this field is compounded by rapid changing technology, intense national and international competition in the marketplace, rising employee and customer expectations, the demand for improved accountability for the natural environment, strict $\mathrm{OH} \& \mathrm{~S}$-related legislation, and the necessity of working in large, multidisciplinary project teams.

Healthy, safe, and profitable sustainable mineral production techniques are essential to support economic growth. This is ensured through exports in return for muchneeded revenue, as well as exchange of knowledge. In turn, changing external mining environments require novel mining methodologies supported by new and appropriate technologies. The debate around the importance of preparing mining engineers to eventually become leaders and managers is ongoing. Opposing the emphasis on leadership is the argument that the need for specialized technical skills, such as mine planning and design (MP\&D), strata control/rock engineering, mine ventilation, (mine environmental control) (MEC), mineral resource evaluation, and mineral asset valuation is more pressing (Musingwini, Cruise, and Phillips, 2012).

The complexity of mining engineering and the difficulty of teaching and learning in this diverse field are well known. The Engineering Council of South Africa (ECSA, 2015) acknowledges this in their Standards and Procedures System documents, which stipulate a two-phased approach to teaching and learning engineering competence encompassing all areas of specialization at various competency levels. In accordance with ECSA's standards and outcomes of engineering education, the first phase entails acquisition of knowledge through formal tertiary programmes. The second phase entails acquiring practical workplace experience and the application of knowledge to deal with mining-related challenges, including the solving of engineering and related problems. In a report on the status of the education of mining engineering learners internationally, McDivitt (2002, p. 14) confirms that mining engineering learners believe that they need to know more than what they are being taught at university in order to cope with mining engineering-related challenges.

One of the areas in which engineering learners typically need support is that of problem-solving in general, and specifically, the early planning phases, namely, problem structuring (Mingers and Rosenhead, 2004) and problemsolving entailing decision-making (Kluge and Malan, 2011). To assist them in solving given problems more easily, and to produce the best products in the shortest time and at the lowest cost (Wallace and Burgess, 1995, p. 429), engineering learners use tools and methods to alleviate their cognitive load (Goel, 1995). In the same manner, educators develop and use tools to guide their teaching and to facilitate the learning process that mirror the way experienced and competent engineers work and think (Haupt, 2015).

The purpose of this article is therefore to explore the possibilities of a novel, generic, yet integrated framework for problem-solving within discipline-specific learner education and development modules at the Department of Mining Engineering at UP. This would serve as an educational tool to guide learners in considering the psychology of extended cognition behind solving mining engineering problems, especially within the context of the CDIO problem-solving methodology. This framework represents the intangible world of extended cognition of the typical mining engineer (Webber-Youngman and Calaghan, 2011) and is a response to the need for streamlining the transfer of knowledge (van der Merwe, 2011).

\section{Background to problem-solving}

Transferring the latest knowledge and thinking skills to new learners, as well as to an older generation of experienced mining engineering practitioners, is one of the pursuits of mining engineering education. The general approach of tertiary institutions offering mining engineering degrees is, in the first two years of the academic engineering programme, to engage learners in knowledge and understanding of content and science-related tasks. These are related to disciplines including mathematics, chemistry, geosciences, and physics. In accordance with the convention in engineering courses over the past six decades, the first two years are thus devoted to 'engineering sciences' (McDivitt, 2002). The Washington Accord internationally agreed educational pathways for qualifying engineers require that the first two years of study include relevant science-related courses as applied in particular specialization fields (IEA, 2009). These serve as a foundation for analytical thinking, where learners are required to apply scientific principles to technological problems (Dym et al., 2005). Engineering education literature (Jonassen, Strobel, and Lee, 2006; Dym et al., 2005) overwhelmingly indicates that traditional curricula propagate linear thinking, which is not conducive to fostering the kinds of thinking needed when working in environments with complex systems.

The ensuing limitation on nonlinear processing of information leaves mining engineering graduates entering the workplace ill-equipped to contemplate the variety of problems that they are given to solve, and to connecting them consciously to a theory-based cognitive process. The aftermath of this limitation is a ripple effect where engineering practitioners who do not clearly identify the type of problems they are dealing with have little chance of effectively analysing and researching given problems by consciously integrating internalized and externally emerging information. Furthermore, their opportunities to intentionally find and unexpectedly discover new information, and interpret it as relevant to the problem or its potential solution, subsequently tend to be less focused. Therefore, there is a real danger of making unfounded assumptions before 


\section{Engineering education: an integrated problem-solving framework}

investigating all possible sources of information. Ultimately this might lead to a limited set of professional and personal judgmental skills. In order to address restrictive information processing opportunities when teaching and learning ways to solve mining engineering problems, a new approach seems necessary.

Since 2011, the mining engineering department at UP has purposefully engaged in improving its entire offer of discipline-specific knowledge to learners enrolled for the four-year degree in pursuit of contributing to the developing learners' professional skills set. Several measures were taken specifically in the areas of content of MP\&D, development of the discipline-specific profile, academic support, communication, and teaching. In the area of content, the unknown physical and intellectual world of the mining engineering practitioner has been addressed by developing simulations through instructional design and virtual reality (Webber-Youngman and Calaghan, 2011).

To improve the development of the discipline-specific profile of mining engineering learners, various psychological instruments have been implemented in the fourth year of the programme at the exit level. These include the Myers Briggs tool; DISC analysis (dominance, influence, compliance, and steadiness), measuring personality and group tendency relationships; Herman's Brain Dominance Instrument tool, determining thinking preferences; and the Shadowmatch tool, establishing dominant thinking habits. In addition, the emotional intelligence of final-year learners is tested to provide them with a better understanding of their ability to deal with difficult emotional situations and decisions in their careers.

There is evidence (Webber-Youngman and Calaghan, 2011) that learners have benefited from these various interventions and tools. However, when evaluating the fourth-year mining MP\&D projects, mentors identified a prevailing limitation in the ability of learners to efficiently identify and understand the nature of the mining problems they are required to solve. In part, this might be attributed to learners' lack of appropriate exposure to real mining processes and problems. In addition, it might also be ascribed to the fragmentation of cognitive strategies and support focusing on the individual differences amongst learners within groups. There is also fragmentation in solving linear problems without accounting for generic and unseen nonlinear problem-solving skills that encompass content knowledge and process methodologies. This seems to be a problem with other engineering disciplines as well.

Further research is needed to establish how the cognitive measures that are currently implemented contribute to generic, nonlinear thinking. The ability of learners to integrate their internalized linear thinking tendencies with unexpected information that is typically encountered when involved in the early phases of the problem-solving process also requires research. Early phases here refer to understanding and structuring a given problem through conception, and incrementally solving it in stages through a critical thinking process (Haupt, 2015), which is discussed later in more detail.

The literature on engineering education research, in general, tends to focus on the problem-solving phase, which emphasizes the quality of the end products or solutions and disregards the importance of the problem structuring phase
(Eastman, 2001). The same is true of the methodologies and problem-solving models available to learners and competent engineering practitioners.

Well-known problem-solving models, which include the Russian model Teoriya Resheniya Izobretatelshkikh Zadatch (TRIZ) translated as 'Theory of Inventive Problem Solving' (Barrie, Domb, and Slocum, 2010), are seen as being onesidedly focused on finding the solution without sufficient attention to the research-driven process of identifying the problem. It is this limitation that this article attempts to address at a theoretical level, aiming to understand how to further improve the Mining Engineering module Introduction to Project in the third year of mining engineering studies.

Another well-known approach to solving engineering problems, suggested by Kepner and Tregoe (1981), involves finding the root causes, using cause-and-effect analysis of a particular problem. However, they do not differentiate between different types of problems. Literature exploring the nature of a problem and its effect on the dynamics of the problem-solving process, introduced by Simon (1973), provides important insights into the importance of the problem structuring phase.

There is a general need to guide learners in their discipline-specific development modules to a generic problem-solving methodology that is suitable for the multiple and diverse contexts of mining engineering practice. Based on this need, the authors developed an integrated problemsolving framework that serves as a teaching and learning tool. For this purpose, the most recent addition to the empowering tools in the third and fourth year learners' discipline-specific cognitive toolbox is the inception of the Theory of CDIO (Platanitis and Pop-Iliev, 2012) methodology. This provides a structured methodological context within which problem solving might be taught and learnt. The conceptualization of CDIO is based on the philosophy of 'design thinking', where 'design' implies a generic approach to 'problem solving' in a mine planning and design thinking environment, irrespective of the engineering discipline or specialization.

As such, CDIO is meant to guide learners in solving technical, systemic, and business-related problems that are typical of the mining context. However, as CDIO is a broad model, encompassing multiple aspects in a transdisciplinary manner, curriculum designers need to continuously update a careful and detailed mapping of the entire four-year mining engineering programme to ensure a well-balanced implementation of the model.

The authors suggest an integrated cognitive approach to problem solving in mining engineering education where the CDIO methodology is used as a context for teaching and learning particular cognitive skills. However, despite the value of the CDIO methodology as a context in engineering and business learning environments (Alarcon et al., 2013), the authors argue that learners applying the suggested stages is, in itself, not sufficient. It does not provide satisfactory guidance for lecturers and learners to become sensitive to the microscopic complexities involved in the extended nature of the underlying early cognitive phases of problem solving. By understanding some aspects of the psychology of extended cognition as a backdrop, the authors aim to strengthen the professional capabilities of senior (exit-level) mining engineering learners. 


\section{Engineering education: an integrated problem-solving framework}

\section{Theoretical foundation - a psychological perspective}

In order to guide the development of suitable curricula and teaching methodologies that might effectively foster information processing, two theoretical underpinnings seem to play an important role. The first set of theories concerns the ontological issues around microscopic information processing, known as design cognition. This is also, as mentioned earlier, known as the intangible world of mining engineering. The second set of theories concerns the methodological issues around the structuring of activities towards the effective solving of engineering problems. This is also known as the visible outer world of activities of the mining engineering practitioner.

The concept of design cognition is derived from the notion of design thinking as a form of problem solving which has planning at its core. As such, 'designing' is considered as an intentional mental activity precluding the early planning and does not refer to the production of the end product. Therefore, MP\&D and 'problem solving' here are used interchangeably. The Theory of Human Problem Solving was conceptualized by Newell and Simon (1972) as a generic psychological process that could be scientifically studied and recorded by understanding the processing of information by humans. This theory focused on the internal computational processing of information, which became known as an abstract problem-solving space theory. In response to its onesided emphasis on the unseen, intangible processes involved, Gibson (1986) introduced the notion of perception as a form of external information processing, which assumes that external objects afford useful information.

A theory that supports the combination of internal and external information processing as the underlying principle of problem solving is known as Extended Cognitive Theory (ECT). It is also termed Situated Design Cognition (SDC) (Gero and Kannengieser, 2006). An extended approach accounts for the complex dynamics involved in making connections between perceivable information about the material characteristics of objects, people, and contexts, and theoretical knowledge in order to make sound scientific, technical, and professional judgements and decisions when solving problems. This dynamic is the ontological basis of problem-solving methodology (Haupt, 2017). However, although this concept has been explored in various designrelated environments, such as architecture (Suwa and Tversky, 1997), industrial design (Haupt, 2015), and mechanical engineering (Goel, 1995), it has not been articulated explicitly in a mining engineering context.

This thinking regarding engineering methodology as an intellectual activity originated in the 1960s (Cross, 1986). Researchers became interested in the intangible world of engineering practice and studied the cognitive processes involved in their problem-solving activities. The primary approach to such research was to study the ways in which engineering practitioners intentionally process information in the early phases of understanding a particular problem, and planning how to solve it. Two opposing psychological approaches ensued from this interest. On the one hand are the computational theorists, such as Simon (1969), who considered information processing as an internal process using internal sources of knowledge. On the other hand are the ecological psychologists, who advocated the use of external information sources and processes that form part of an engineering practitioner's physical environment when solving a given problem. A third view was developed in the late 1990s that attempts to combine these two opposing views and integrate these into an extended cognition paradigm. The authors subscribe to the assumptions of the latter to explain problem-solving and develop disciplinespecific learning curricula for mining engineering learners.

However, despite the differences between these approaches, a common pool of assumptions that conceive the engineering or specifically MP\&D process prevails. Irrespective of the particulars of the specialization knowledge and skills involved, and the complexity of the particular problem that competent engineering practitioners and learners are given to solve, the process involve a common sequence of steps through which engineers move. These steps can be summarized as follows:

> Identification, exploration, decomposition, and analysis of the problem

> Identification of the connections between the components

> The solution of the sub-problems in isolation

> Finally, the synergistic combination (taking into account the interconnections) of the partial solutions into the problem solution (Goel and Pirolli, 1989).

Based on these observations, engineering theorists (Simon, 1996) concluded that the act of thinking in an engineering manner is largely independent of the objects or systems that are involved.

The implication for engineering education, irrespective of the particular discipline, is that although sourcing and obtaining information per se is not considered as the solution to a given engineering problem, it is an essential sub-process of both cognitive phases at issue here, i.e. problem structuring and problem solving (Simon, 1973). In the case of the problem-structuring phase, engineers are often provided with insufficient information to clearly identify or define the engineering problem at hand, as is the case in illstructured (mining) engineering problems. In the case of the problem-solving phase, engineers incrementally detect gaps in their information, especially in complex problems where multidisciplinary fields of specialized knowledge are required to develop a suitable solution or sub-solutions (Wiltschnig and Christensen, 2013). Sourcing and obtaining such information therefore forms in integral part of the problemsolving phase of the design process.

An extended cognition approach was adopted in this article. The implication thereof for mining engineering education is that learners require guidance in deliberate problem-solving strategies. This is needed to extend their intangible internal world of mining, science and mathematics, and applied engineering knowledge and information stored in their long-term memories to include their outer, physical, socio-economic world. They need to interact with the real, physical world surrounding the problem in order to identify the problem, its root cause, and search for information that might help them to find a solution.

Observations from empirical protocol studies over the past twenty years (Goel, 1995; Haupt, 2015) where the micro-processes of experts, experienced and competent planners, and designers solving problems have convincingly 


\section{Engineering education: an integrated problem-solving framework}

shown a stable pattern of information processing distributed over two distinct cognitive phases, irrespective of the methodology that the participants were trained to use. The two early cognitive phases can be summarized as follows.

> Problem structuring through a process of observation, inquiry, research, analysis and interpretation, redefining, and explicit making of the real engineering problem or desired outcome to be achieved

> Problem solving through a three-pronged sub-process:

a. Conceptualizing a solution through preliminary ideas

b. Developing suitable ideas

c. Refining ideas and producing blueprints and preferred plan(s) to be implemented and operationalized.

These early phases subsequently result in the 'late cognitive phases' during which the refinement of ideas and commitment to a particular conceptual solution is ultimately explicitly formulated and visualized in formats ready for construction and implementation. For educational purposes, it is important to emphasize that cognitive phases overarch the seeming linear approach listed above. The latter serve as a useful way of separating cognitive activities.

However, much research has shown that the mental processes of engineers during the problem-structuring and problem-solving phases cannot be described as a linear process. The cognitive phases, as well as the implied engineering activities, often overlap in what Goel (1995) terms a 'leaky phase', which is implied in the application of 'limited control' indicated in Table I, item 4. Table I is a summary of the typical psychological characteristics of the intangible information processes during the early phases of the design process identified by Goel and Pirolli (1992) in protocol studies on a variety of designers, including engineers.

The concept 'early phases', which is the focus of this article, entails the understanding of the problem by interpreting the given brief, and restructuring and redefining it until the desired outcome of problem-solving processes is mentally clear and represented in the form of sketches, diagrams, and models. Intertwined with structuring and defining the problem, is the coincidence of the 'later phases', entailing the generation of an appropriate solution and its subsequent incremental development and refinement. Finally the generated solution to which engineers commit themselves (Table I, item 5), and in which they state/define the problem or desired outcome of the problem in the particular project during the problem-structuring phase, is mentally and visually developed and refined into a useful blueprint specifying the construction and implementation of an envisaged artefact, process, or system during the final

\begin{tabular}{|c|c|}
\hline Psychological characteristic & Information processing \\
\hline 1. Extensive problem structuring. & $\begin{array}{l}\text { Identification, exploration, and analysis of the given problem. } \\
\text { Establishing the scope of the problem. }\end{array}$ \\
\hline 2. Extensive performance modelling - problem-solving. & $\begin{array}{l}\text { Incremental process of conceptualizing functionality and } \\
\text { subsequent physical components making efficiency, } \\
\text { sufficiency, and desired performance of an artefact or system } \\
\text { possible. }\end{array}$ \\
\hline $\begin{array}{l}\text { 3. Personal and institutional evaluation } \\
\text { and application of standards. }\end{array}$ & $\begin{array}{l}\text { Personal and institutional knowledge of domain-specific } \\
\text { knowledge of standards and norms. } \\
\text { Determination of institutional and personal value system to be } \\
\text { considered. }\end{array}$ \\
\hline $\begin{array}{l}\text { 4. Limited control mode strategy with nested } \\
\text { evaluation cycles. }\end{array}$ & $\begin{array}{l}\text { Deliberate control of cycles of exploration, evaluating } \\
\text { information, and generation of ideas. Controlling delay as well } \\
\text { as acceleration of decision-making and commitment to both } \\
\text { problem identification and solution development. }\end{array}$ \\
\hline 5. Making and propagating of commitments. & $\begin{array}{l}\text { Idea generation, decision-making, testing and developing } \\
\text { implementation plans. Committing to decisions implied and } \\
\text { explicated in redefinition of the problem or desired outcome of } \\
\text { the solution. }\end{array}$ \\
\hline 6. Solution decomposition into leaky modules. & $\begin{array}{l}\text { Analysis of solution, evaluation, searching for more } \\
\text { information, integrating suitable information, discarding } \\
\text { irrelevant information and unsuitable ideas, developing } \\
\text { solution further. }\end{array}$ \\
\hline $\begin{array}{l}\text { 7. Hierarchical considering abstract theories } \\
\text { and principles. }\end{array}$ & $\begin{array}{l}\text { Transforming generalized abstractions such as intended goals } \\
\text { and aims, including philosophy and functionality, into } \\
\text { practical and tangible object and system specifications. } \\
\text { Use of multidisciplinary knowledge. Use of domain-specific } \\
\text { knowledge. }\end{array}$ \\
\hline $\begin{array}{l}\text { 8. Use of visual modes of knowledge and decision- } \\
\text { making representations. }\end{array}$ & 2D and 3D modeling of ideas, processes, and decisions. \\
\hline $\begin{array}{l}\text { 9. Extensive interaction with external sources of } \\
\text { information emerging from the physical environment. }\end{array}$ & $\begin{array}{l}\text { Reliance on perception, detecting sensorial information } \\
\text { afforded by basic primitives including sound, smells, visual, } \\
\text { tactile, and taste. }\end{array}$ \\
\hline
\end{tabular}




\section{Engineering education: an integrated problem-solving framework}

refinement phase of the design process. The basis for this theory of the early phases of the design process can be found in the numerous descriptive and explanatory protocol studies conducted over the years on engineering practitioners (Goel and Pirolli, 1992; Haupt, 2015; Cross and Clayburn, 1998), and specifically mechanical engineers, industrial designers and architects.

During their third year of study, the learners in the UP Mining Engineering Department in their discipline-specific development modules are introduced to the early cognitive phases through non-mining problem-solving case studies where they need to identify the two cognitive phases, namely problem structuring and problem solving. These case studies are carefully selected from business management or service design contexts involving a variety of types of problems. The focus is thus on the subsequent deliberate search for missing information and its appropriate application. Engaging analytically with the case studies serves to familiarize learners with the generic theoretical background of the process that they are expected to encounter during their fourth (final) year of study.

Learners are also required to deconstruct these case studies in terms of the types of problems (Table II), the search for information, and the identification of relevant information-processing activities (Table I). Abstract Cognition Theory is concretized through a team teaching strategy where the authors, a mining engineering practitioner, and a cognition specialist collaborate in the contextualization of the theory. The focus of such an intervention is on the intangible psychological characteristics typical of the search for information in each particular cognitive phase of the problem-solving process. Two assumptions are important here. The first is that the particular type of problem given determines the specificity of information available to understand its scope and implications. The second assumption underlying the search for information is that problem-solvers do not have sufficient information when given particular problems, depending on their ill-structured or well-structured nature.

From a cognitive perspective, information processing is seen to take place in a system consisting of three stages. The first is the start stage, typified by the vagueness and/or incompleteness of input information. The second is the transformation stage, typified by the change from vagueness to concrete, specific, sufficient and accurate information. The third stage entails the solution, with detailed specifics of the decisions made (Goel, 1995). The difficulty for the mining engineering learners lies in understanding how the structure of a given problem influences their search for information. The learners in the final year of study typically find that the openness and relative ill-structured nature of some of their project tasks presents difficulties, as they are neither sufficiently educated nor trained in classifying these types of problems, and lack experience in identifying the relevant missing information.

As a result of the abovementioned factors, learners often follow an inappropriate cognitive approach to solve problems. Their linear and prescriptive education in respect of science and mathematics training contributes to their uncertainty in a mental space where the pathway to a specific solution has not been outlined. In order to familiarize them with some of the uncertainty that they should expect in their projects, the authors believe that, at most, a set of descriptive characteristics that are typical of those experienced by competent engineering practitioners and other designers can be introduced to the learners. These characteristics, in which uncertainty is embedded, are summarized in Table I. The determinant factor of this set of psychological characteristics is the absence of information concerning a particular problem presented for solution. This absence, in turn, is determined by the type of problem that competent engineering practitioners are given, ranging from relatively small-scale, well-structured technical problems to large-scale, complex, ill-structured planning and design problems with mediumscale semi-structured optimization problems.

The advantage for lecturers of understanding the cognitive characteristics summarized in Table I lies in its focus on the process and not on the final product. This might assist them in detecting the growing maturity of learners' ability to channel their uncertainty in a rational and systematic manner through their MP\&D projects. As such, it is not meant as a prescriptive set of rules or steps for learners to follow. These are unseen, intangible processes that result in the decisions that they take. Only when learners are guided/coached to physically and sensorially integrate what they perceive on surface or underground, in shafts, in production areas, or transportation systems with the theoretical models that they learn at universities can they develop meaningful cognitive connections/alignments between real-life mining problems, the knowledge they have acquired, and the methodologies that they select to apply.

\section{The role and types of problems}

In terms of the Theory of Extended Cognition, the availability of information at the start of a given problem is determinant to the dynamics of the entire problem-solving process. Simon (1969), in his seminal work Sciences of the Artificial, began the important task of theorizing about different types of problems - namely, well-structured, semi-structured, and illstructured problems. The role of these types of problems is directly connected to the amount of information typically known and accessible to engineering practitioners and the associated psychological characteristics summarized in Table I. Therefore, to deepen learners' understanding of the dynamics involved in solving real-world mining problems and the associated uncertainties, the authors devised a classification system (Table II) for the various types of typical of mining engineering problems. This is based on the theory of well-structured and ill-structured problems, posited by Simon (1972) and developed by Rittel and Webber (1984).

The quality, applicability, and in many cases volume and availability or lack of information at the start of any engineering project determines the extent of the learner's or engineering practitioner's uncertainty. This can range from relatively low levels of uncertainty to extensive uncertainty in all phases of the process. Entry-level mining engineering practitioners are typically given the first type of problem on the one extreme of the available range, here termed 'repair/replacement tasks' (Table II). These might be considered as 'well-structured problems' as the goal of the task is known to the engineering practitioner, as well as they process involved in solving it. 


\section{Engineering education: an integrated problem-solving framework}

\begin{tabular}{|c|c|c|c|}
\hline \multicolumn{4}{|c|}{$\begin{array}{l}\text { Table /I } \\
\text { Types of mining engineering problems and its implications for information search }\end{array}$} \\
\hline \multirow[b]{2}{*}{$\begin{array}{l}\text { SEARCH FOR } \\
\text { INFORMATION }\end{array}$} & \multicolumn{3}{|c|}{ TYPES OF MINING ENGINEERING PROBLEMS } \\
\hline & $\begin{array}{l}\text { Repair tasks } \\
\text { Well-structured problems }\end{array}$ & $\begin{array}{l}\text { Optimization tasks } \\
\text { Semi-structured problems }\end{array}$ & $\begin{array}{l}\text { Design/innovate tasks } \\
\text { Ill-structured problems }\end{array}$ \\
\hline $\begin{array}{l}\text { Availability of } \\
\text { information }\end{array}$ & $\begin{array}{l}\text { 'Well-structured'. Information } \\
\text { available through existing } \\
\text { knowledge regarding existing } \\
\text { similar objects and systems. }\end{array}$ & $\begin{array}{l}\text { 'Semi-structured'. Some } \\
\text { information is known through } \\
\text { existing knowledge and can be } \\
\text { adopted in objects, tools, and } \\
\text { systems. Much room exists for } \\
\text { novel ideas to be integrated and } \\
\text { combined into existing objects and } \\
\text { systems. }\end{array}$ & $\begin{array}{l}\text { 'Ill-structured'. No information about } \\
\text { the solution or its pathway is known. } \\
\text { Extensive uncertainty exists about the } \\
\text { end product or process to achieve it. }\end{array}$ \\
\hline Extent of uncertainty & Relatively little uncertainty. & $\begin{array}{l}\text { Some uncertainty exists about some } \\
\text { of the aspects of the process and } \\
\text { end product. }\end{array}$ & $\begin{array}{l}\text { Extensive uncertainty about most } \\
\text { aspects of the process and end product } \\
\text { exists. }\end{array}$ \\
\hline $\begin{array}{l}\text { Starting point of } \\
\text { search }\end{array}$ & $\begin{array}{l}\text { Identify the faulty component } \\
\text { presenting symptoms. }\end{array}$ & $\begin{array}{l}\text { Problem contemplation: } \\
\text { Mission contemplation, } \\
\text { Existing objects, processes, } \\
\text { tools/system/technology. } \\
\text { Search for areas in need of } \\
\text { improvement. }\end{array}$ & $\begin{array}{l}\text { Problem contemplation: } \\
\text { Mission, need (new objects, processes, } \\
\text { tools, systems), } \\
\text { Intentions (functionality), } \\
\text { Required behaviour, impact, brief, } \\
\text { community, and environment. }\end{array}$ \\
\hline Focal point of search & $\begin{array}{l}\text { Identify the real causes of } \\
\text { deficiency. } \\
\text { Constraints are well defined and } \\
\text { known. }\end{array}$ & $\begin{array}{l}\text { Modification to artefact/system, } \\
\text { interaction with people, and } \\
\text { context, subject to constraints and } \\
\text { restrains. }\end{array}$ & $\begin{array}{l}\text { Constraints, restraints, required } \\
\text { structure/system, behaviour, interaction } \\
\text { with people, and context. }\end{array}$ \\
\hline $\begin{array}{l}\text { Core reasoning } \\
\text { process }\end{array}$ & $\begin{array}{l}\text { Determine corrective measures: } \\
\text { Application of known domain- } \\
\text { specific knowledge and } \\
\text { experience. }\end{array}$ & $\begin{array}{l}\begin{array}{l}\text { Analysis, evaluation and } \\
\text { improvement/refinement }\end{array} \\
\text { Application of known domain } \\
\text { specific knowledge. }\end{array}$ & $\begin{array}{l}\text { Planning and design: discover and } \\
\text { refine/rework unknown and known } \\
\text { information. }\end{array}$ \\
\hline $\begin{array}{l}\text { Sources of } \\
\text { information }\end{array}$ & $\begin{array}{l}\text { Recall internal domain-specific } \\
\text { knowledge recalled from memory. } \\
\text { Access external information } \\
\text { accessed through visual } \\
\text { perception of current problem } \\
\text { situation. }\end{array}$ & $\begin{array}{l}\text { Recall internal domain-specific } \\
\text { knowledge recalled from memory. } \\
\text { Access external information } \\
\text { accessed through visual perception } \\
\text { of current problem situation. }\end{array}$ & $\begin{array}{l}\text { Recall internal domain-specific } \\
\text { knowledge recalled from memory. } \\
\text { Recall internal knowledge from } \\
\text { personal experience of similar and } \\
\text { different problem situations. } \\
\text { Access external information through } \\
\text { multiple direct perceptions of current } \\
\text { problem situation and its constraints. }\end{array}$ \\
\hline End goal of search & $\begin{array}{l}\text { Restore the things back the way } \\
\text { they were. }\end{array}$ & $\begin{array}{l}\text { Improve physical and procedural } \\
\text { characteristics of existing } \\
\text { systems/objects. }\end{array}$ & $\begin{array}{l}\text { Create something new that does not } \\
\text { exist yet. Innovative. Apply basics } \\
\text { Potential for multiple unknown } \\
\text { constraints. }\end{array}$ \\
\hline $\begin{array}{l}\text { Scope of the system } \\
\text { involved }\end{array}$ & $\begin{array}{l}\text { Contained in one artefact or } \\
\text { component thereof. }\end{array}$ & $\begin{array}{l}\text { Singe component within a complex } \\
\text { system, or more than one } \\
\text { component in a range of artefacts, } \\
\text { which form part of the system. } \\
\text { A single change might optimize the } \\
\text { entire system. }\end{array}$ & $\begin{array}{l}\text { Large, complex, new artefacts or } \\
\text { systems operating on the basis of novel } \\
\text { principles/technology, supported by } \\
\text { basic science and applied engineering } \\
\text { knowledge. }\end{array}$ \\
\hline
\end{tabular}




\section{Engineering education: an integrated problem-solving framework}

The second type of problem is an optimization task, which entails some uncertainty as the aim is typically to improve elements, functionality, and effectivness of an existing object, tool, or system. At the other extreme is the third type, 'design' or 'innovation' tasks, which usually pose extensive uncertainty as to most aspects of the desired outcome and the process by which it is achieved. These types of problems are known as 'ill-structured' because of the extensive lack of sufficient and appropriate information at the start of the task (Rittel and Webber, 1984). They also usually lack specific and relevant information about the nature of the object, tool, or system that is being designed as they aim to create something that does not yet exist using basic scientific and applied engineering knowledge. Until it has been tested, the functionality and efficacy of the new object, tool or system - although it might be predicted - is largely unknown (Goel, 1995).

Only when learners/engineering practitioners are experienced and considered competent should they be charged with solving MP\&D and innovation problems. In order to guide the third-year mining engineering learners through the 'search for information' process and its subsequent movement from low to high/acceptable levels of certainty, the different types of problems that learners are likely to encounter as they progress through their professional careers are summarized in Table II. Developing their theoretical grasp of what they might expect in their final-year projects, the learners are then introduced to a stage-based model of the MP\&D processes, namely, CDIO.

\section{CDIO - a problem-solving methodology}

CDIO as design or problem-solving methodology was conceived at the Massachusetts Institute of Technology (MIT) in the late 1990s. In collaboration with the Swedish universities Chalmers University of Technology, Linkoping University, and the Royal Institute of Technology, the CDIO initiative was formally founded in 2000 (CDIO ${ }^{\mathrm{TM}}$ Initiative, 2003) as an audacious undertaking that would transform engineering education in the USA and Europe. With the participation of academics, industry, engineering practitioners, and learners, a stage-based framework was developed for engineering fundamentals that serves as a context in which particular descriptive cognition activities occur. The CDIO stages have been distilled from well-known models, including those of Pahl and Beitz (1996) and French (1999):

> Conceiving: this entails defining a particular need, describing the problem or desired outcomes, and connecting it with an appropriate technology that could fulfill it, while considering the strategies and regulations embedded in the company involved. This early phase leads to the development of a concept, and structural and business decisions to be made

> Designing: this involves drawing up the plans, models, algorithms, or formulae that provide blueprints of what will be implemented in the later stages of the process

> Implementing: this late phase comprises transforming the plans into the solution, which could be a product, system, or intervention
> Operating: this is also a late phase, which entails the use of the implemented product to deliver the intended function/desired outcome, inclusive of its entire lifecycle.

The advantage of this methodological framework is that it is universally adaptable and lends itself to multiple contextual applications. The CDIO framework has the further advantage that it does not restrict engineering practitioners to a linear step-by-step process, but allows for iteration and movement between the early and later stages. It furthermore allows for the translation of stages and sub-stages into cognitive activity concepts, making the theoretical and practical integration of isolated early phases with early D\&P cognition phases and consequential educational implications possible. For the purpose of this article, the focus is on the first two stages, conceiving and designing, which translates to the two early cognitive phases, problem structuring and problem solving, at issue here.

\section{An integrated problem-solving framework}

The purpose of the proposed descriptive problem-solving framework in this article is to guide the facilitation of mining engineering education projects undertaken by learners in their final year of study. As such, as seen from Figure 1 and Figure 2, it integrates elements of the CDIO methodology and activities (Table I) from the Theory of Extended Cognition. The first step in the integration process is to map the two early cognitive phases, problem structuring and problem solving, onto the stages of the CDIO model, namely Conceive, $\mathrm{D} \& \mathrm{P}$, Implement, and Operate, as seen in Figure 1. The second step is to populate the overlaps with cognitive activities that are relevant to each of the overlaps, as visualized in Figures $2 a$ (Conceive) and $2 b(D \& P)$.

Each of the overlapping areas between CDIO phases and cognitive activities, as represented by the blank triangles in Figure 1, are amplified in Figures $2 \mathrm{a}$ (Conceive) and 2b $(\mathrm{D} \& \mathrm{P})$. Each of the overlapping areas between CDIO phases and cognitive activities, as represented by the grey triangles in Figure 1, are amplified in Figures $2 \mathrm{a}$ (Conceive) and $2 \mathrm{~b}$ $(D \& P)$. For purpose of economy, in the 'Conceive' $(C)$ triangle in Figure 2a, the cognitive phase, mission and conceptual $D \& P$ activities have been presented in a linear manner. The ' $\mathrm{D} \& \mathrm{P}$ ' triangle received the same linear treatment in Figure 2. However, not only do the individual items treated in this way interact with one another; they also depend on each other. Furthermore, the two triangles also interact with each other in a co-evolutionary manner, indicated by the crisscrossing connection between the two triangles at the centre. Coevolution is an acknowledged (Cross and Dorst, 1998) cognitive phenomenon in the methodology of engineers. This implies that, when solving engineering problems, engineers concurrently and simultaneously move between seeking to understand a given problem or aspects thereof and developing potential solutions. It is therefore necessary that training in problem solving should not enforce linearity, but allows engineering learners to iteratively and dynamically move between problem structuring and problem solving. 
Engineering education: an integrated problem-solving framework

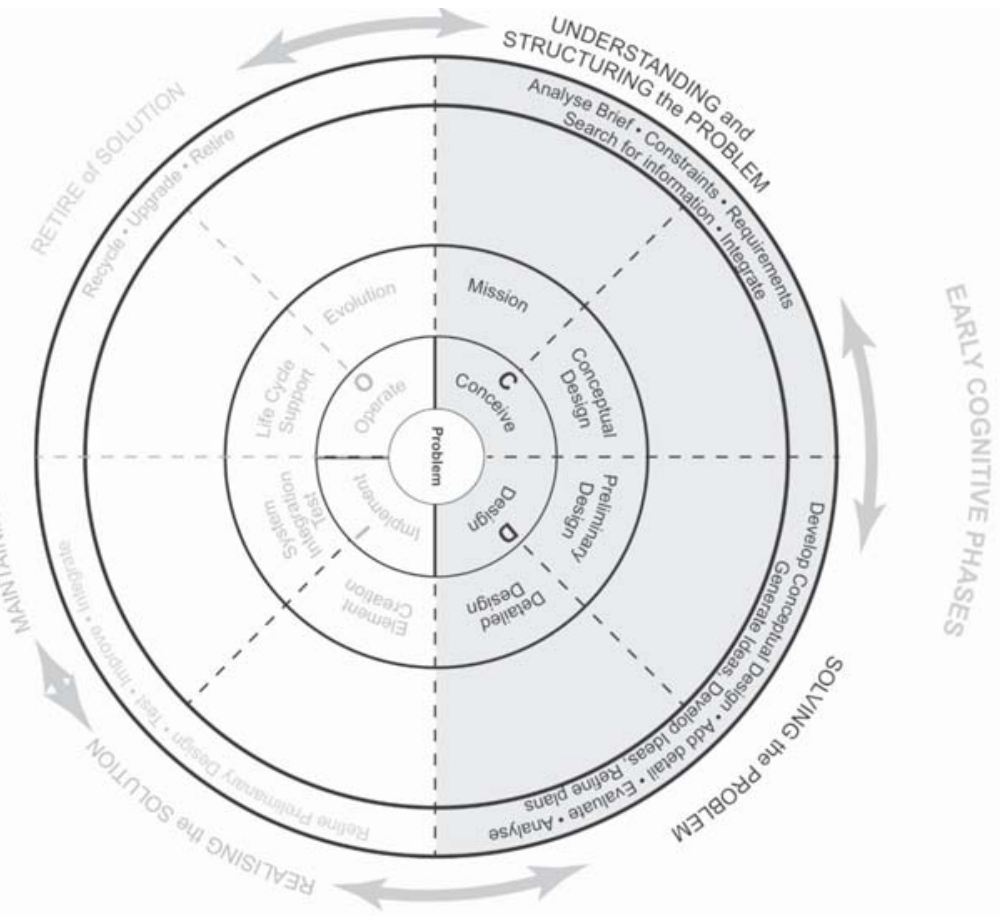

Figure 1-Model of an integrative framework, cognitive phases onto CDIO stages

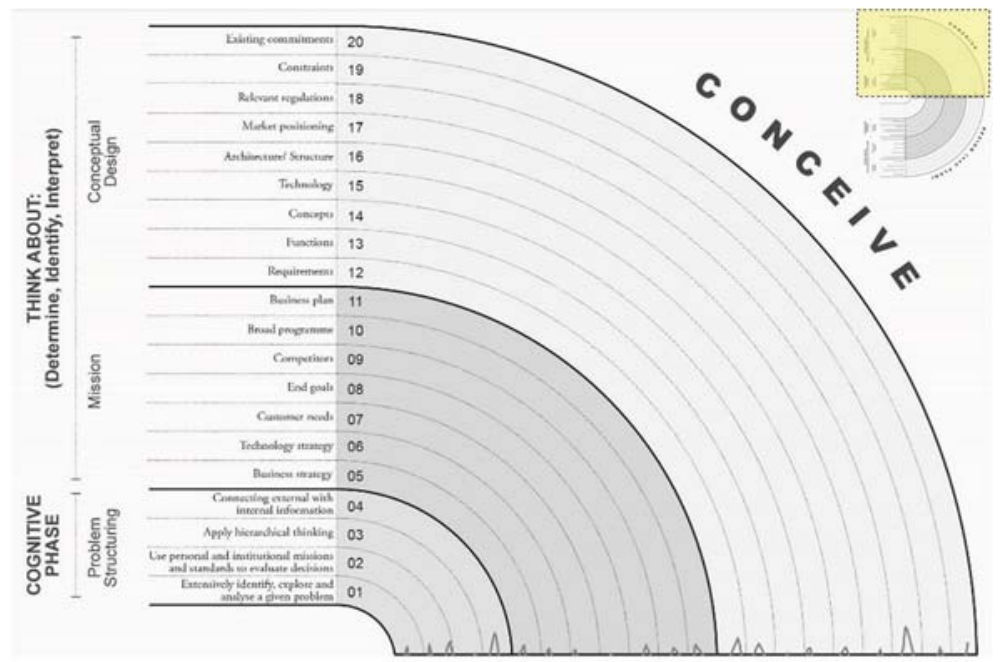

Figure 2a-Mapping early cognitive activities onto early CDIO stages (Conceive)

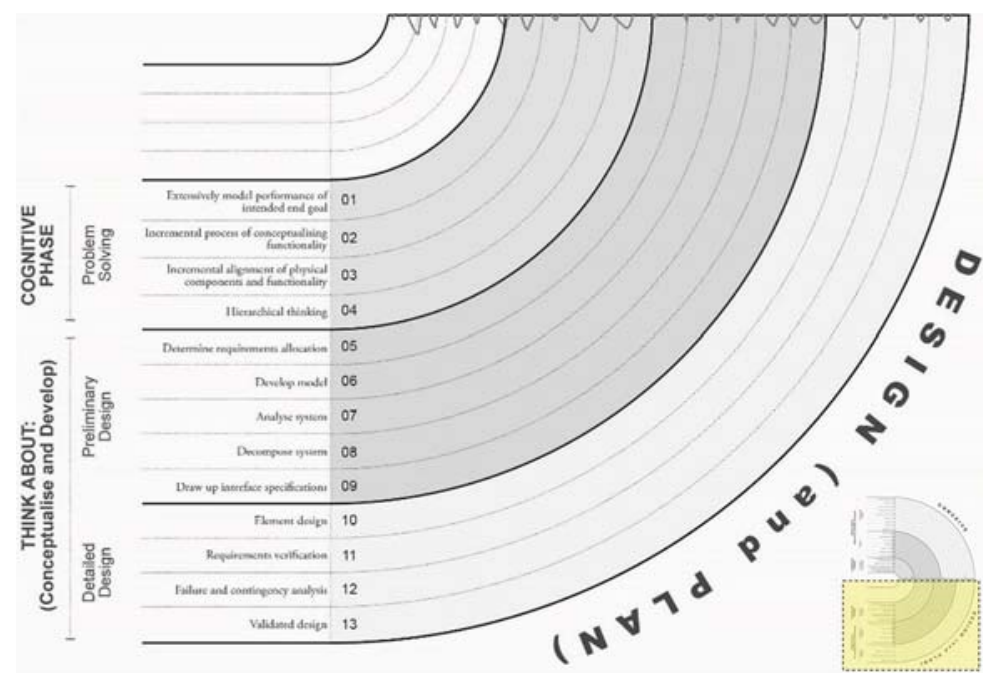

Figure $2 \mathrm{~b}-$ Mapping early cognitive activities onto early CDIO stages (D\&P) 


\section{Engineering education: an integrated problem-solving framework}

\section{Conclusion}

The descriptive integrative framework introduced in this article is strongly focused on the technical aspects of problem-solving methodology, describing the early cognitive phases, problem structuring, and problem solving. It described the activities thought necessary to progress from understanding the problem to solving it. It further described how this overlaps with the CDIO stage of conceiving the nature of a problem or need, and connecting it through integrating relevant internal knowledge and external information. The use of appropriate technical concepts that could fulfill the need or solve a particular problem was also discussed, as this takes place within the confines of a given structural and business context.

The problem-structuring phase is followed by the problem-solving phase, which is divided into sub-phases. The first sub-phase, preliminary design, overlaps with the Conceive stage and the D\&P stage. Conceiving of a suitable solution, however, implies a clearly defined problem with a transparent description. This sub-phase includes cognitive activities that allow engineering practitioners to move simultaneously and seamlessly between searching for more information about the nature of the problem and its components, and conceptualizing initial ideas for a suitable solution. Progressing to the next cognitive sub-phase, Developing, seems to coincide with the CDIO stage of designing. The cognitive activities involved here allow engineers to visualize their ideas by drawing up plans, algorithms, formulae, or layouts. This entails the addition of details and multiple iterations as a result of the critical evaluation of decisions and ideas. The refinement sub-phase of the cognitive theory overlaps with the CDIO stage of designing. This involves the refinement and finalization of planning, including implementation instructions and plans for the blueprints.

In educational practice, the value of the integrated model is limited by its product-focused perspective. This implies that the crucial difficulty in facilitating design thinking in mining engineering problem-solving projects lies in finding solutions to technical problems. This is contrary to what happens in reality, where even the most well-structured technical problem-solving process is a highly complex socio-technical and socio-economic responsible cognitive activity, requiring a combination of both microscopic, internal-external information processing skills and a much broader range of skills, ranging from teamwork to human resource management to business management.

In this article it has also been shown that for mining engineering practitioners to become intimately familiar with new trends, new mining methodologies, technology, and practice by generating new knowledge at universities is no simple task. At the UP Mining Engineering Department, the decision to adopt an integrated framework that encompasses technical, managerial, and entrepreneurial problem-solving needs further testing and evaluation. A careful alignment between various components of the discipline-specific education and development module and integrative MP\&D project is necessary. In general, the suggested framework requires further research regarding the way in which it can contribute to the generation and transfer of knowledge. This specifically applies to the synergistic integration of technical knowledge and skills into the development of learners' cognitive profiles in the areas of sustainable information processing skills that are suitable for the 21 st century. This emphasizes the need for an approach to mining engineering education that encompasses discipline-specific knowledge.

The changing context of mining engineering furthermore implies the reconsideration of mining engineering education and its research agenda in the following aspects, as adapted from the CDIO approach (Crawley et al., 2014, p. 28), to current problem-solving contexts:

> Environmental sustainability: a change from mastery of the mining practice area to stewardship of the mining engineering practice area

- Globalization: competitiveness, collaboration, and cooperation, and distribution of engineering activities without the depletion of local expertise through permanent emigration

> Innovation: an emphasis on the delivery of new mining methodology, technology, and goods and services

> Leadership: a new emphasis on engineering practitioners as leaders, not only as managers of enterprises, but also of mining specialization areas and transfer of new knowledge and skills from experienced, competent engineering practitioners

> Entrepreneurship: the creation of new enterprises and the positive economic impact that this has on local communities

> Research: new knowledge about mining engineering practice for a changing environment.

Together, these diverse knowledge and skill focal areas point to a complex world where mining engineering learners need to be able to process information from a variety of sources, and of diverse types, if they want to contribute to solving some of the complex problems that they will inevitably encounter once they enter the world of real work.

\section{Suggestion for further work}

Immersive education through the use of the related technology such as virtual reality, augmented reality, holograms, and 3D printing, to mention but a few, will in future make significant contributions towards understanding and visualizing specific problems and the subsequent enhancement of the development and/or design of related solutions. The cognitive impact of the inclusion of related technology in education, with specific reference to teaching and learning enhancement in the complex problem-solving space, needs to be pursued.

\section{References}

Alarcon, E., Bou, E., Camps, A., Bragos, R., Oliveras, A., Pegueroles, J., Sayrol, E., and Maroues, F. 2013. Designing CDIO capstone projects: a systems thinking approach. Proceedings of the 9th International CDIO Conference, Massachusetts Intitute of Technology, Cambridge. Massachusetts Intitute of Technology and Harvard University. 


\section{Engineering education: an integrated problem-solving framework}

Barrie, K., Domb, E., and Slocum, M.S. 2010. Triz - What is Triz. The Triz Journal. Real Innovation Network. https://triz-journal.com/triz-what-istriz/ [accessed 17 January 2017].

CDIO ${ }^{\mathrm{TM}}$ InITIATIVE. 2003. Wallenberg CDIO Documents. http://www.cdio.org/Wallenberg_docs/wallenberg_docs.html [Accessed October 2016].

Crawley, E.F., Malmovist, J.,Ostlund, S., Brodeur, D., and Edström, K. 2014. Rethinking Engineering Education. The CDIO Approach. Springer, Dordrecht.

CROSS, N. 1986. Understanding design: the lessons of design methodology. Design Methods and Theories, vol. 20. pp. 409-438.

Cross, N. and Clayburn, A. 1998. Expertise in engineering design. Research in Engineering Design, vol. 10. pp. 141-149.

Cross, N. and Dorst, K. 1998. Co-evolution of problem and solution spaces in creative design: observations from an empirical study. Computational Models of Creative Design IV. Gero, J. and Maher, M.L. (eds). University of Sydney.

Dym, C L., Agogino, A.M., Eris, O., Frey, D.D., and LeIFer, L.J. 2005. Engineering design thinking, teaching, and learning. Journal of Engineering Education, January. pp. 103-120.

EASTMAN, C.M. 2001. New directions in design cognition: studies on representation and recall. Design Knowing and Learning: Cognition in Design Education. Eastman, C.M., McCracken, W.M., and Newsletter, W.C. (eds). Elsevier, Amsterdam.

Engineering Council of South Africa. (2015). Standards and Procedures System. Process for training engineering candidates towards professional registration under a Commitment and Undertaking. pp. 1-18. https://www.ecsa.co.za/register/Professional\%20Engineers/R-11P_CnU.pdf

FRENCH, M.J. 1999. Conceptual Design for Engineers. Springer, Dortdrecht.

Gero J.S. and KAnNengieser, U. 2006. A framework for situated design optimization. DDSS. http://mason.gmu.edu/ jgero/publications/2006/06GeroAscona.pdf

Gibson, J.J. 1986. The Ecological Approach to Perception. Lawrence Erlbaum Associates, Hillside, NJ.

Goel, V. 1995. Sketches of Thought. MIT Press, Cambridge, MA

Goel, V. and Pirolli, P. 1989. Motivating the notion of generic design within information-processing theory: the design problem space. AI Magazine, vol. 10, no. 1. https://doi.org/10.1609/aimag.v10i1.726

Goel, V. and PIRolui, P. 1992. The structure of design problem spaces. Cognitive Science, vol. 16. pp. 395-429.

HAUPT, G. 2015. Learning from experts: Fostering extended thinking in the early phases of the design process. International Journal of Technology and Design Education, vol. 254, no. 4. pp. 483-520. http://www.springer.com/journal/10798 [Accessed December 2014].

HAuPT, G. 2017. Design in technology education: current state of affairs. International Handbook of Technology Education. De Vries, M.J. (ed.). Springer, Dortdrecht.

IEA. (2009). Graduate attributes and professional competencies. International Engineering Alliance.

Jonassen, D., Strobel, J. and LeE, C.B. 2006. Everyday problem solving in engineering: lessons for engineering educators. Journal of Engineering Education, vol. 95. pp. 139-151. doi:10.1002/j.21689830.2006.tb00885.x

KePneR, C.H. and Tregoe, B.J. 1981. The New Rational Manager. Princeton Research Press and John Martin, London.

KLUge, P. and MALAN, D.F. 2011. The application of the analytical hierarchical process in complex mining engineering design problems. Journal of the Southern African Institute of Mining and Metallurgy, vol. 111. pp. 847-855.
McDiviTT, J. 2002. Status of education of mining industry professionals. International Institute for Environment and Development and World Business Council for Sustainable Development.

Mingers, J. and RosenHEAD, J. 2004. Problem structuring methods in action. European Journal of Operational Research, vol. 152. pp. 530-554.

Musingwini, C., CRuise, J.A., and Phillips, H.R. 2012. A perspective on the supply and utilization of mining graduates in the South African context Proceedings of the Fifth International Platinum Conference, Sun City, South Africa, 17-21 September 2012. Southern African Institute of Mining and Metallurgy, Johannesburg. pp. 937-952.

Newell, A. and Simon, H.A. 1972. Human Problem Solving. Prentice-Hall, Englewood Cliffs, NJ.

PAHL, G. and BEITZ, W. 1996. Engineering Design. A Systematic Approach. Springer, London.

Platanitis, G. and Pop-Iliev, R. 2012. Self evaluation for compliance with the 12 CDIO Standards. Proceedings of the Canadian Engineering Education Association, June 2011.

https://ojs.library.queensu.ca/index.php/PCEEA/article/view/3652/3666

PCEEA. Proceedings of the Canadian Engineering Education Association. file:///C:/Users/user/Downloads/3652-6470-1-PB\%20(3).pdf [Accessed March 2016]

RitTeL, H.W.J. and WeBBER, M.M. 1984. Planning problems are wicked problems. Developments in Design Methodology. Cross, N. (ed.). Wiley, Chichester, UK

Simon, H.A. 1969. The Sciences of the Artificial. MIT Press, Cambridge, MA.

Simon, H.A. 1973. The structure of ill-structured problems. Artificial Intelligence, vol. 4. pp. 181-201.

Simon, H.A. 1996. The Sciences of the Artificial. MIT Press, Cambridge, MA.

SuwA, M. and TverSKY, B. 1997. What do architects and learners perceive in their design sketches? Design Studies, vol. 18. pp. 385-403.

VAN DER MERWE, J.N. 2011. Future of the South African mining industry and the roles of the SAIMM and the universities. Journal of the Southern African Institute of Mining and Metallurgy, vol. 111, no. 9. pp. 581-592.

WALLACE, K. and BuRGESS, S. 1995. Methods and tools for decision making in engineering design. Design Studies, vol. 16. pp. 429-446.

WebBer-Youngman, R. and CAlaghan, R. 2011. Educating the future mining engineering practitioner. Journal of the Southern African Institute of Mining and Metallurgy, December. pp. 815-820.

Wiltschnig, S., and Christensen, B. T. 2013. Collaborative problem-solution coevolution in creative design. Design Studies, vol. 34. pp. 515-542.

\section{Acronyms}

CDIO: Conceiving, Designing, Implementing, Operating

$D \& P$ triangle: Figure 2: Design and Plan

DISC: Dominance, Influence, Compliance and Steadiness (analysis)

ECSA: Engineering Council of South Africa

ECT: Extended Cognition Theory

IEA: International Engineering Alliance

MIT: Massachusetts Institute of Technology

$M P \& D$ : Mining Planning and Designing

OH\&S: Occupational Health and Safety

SDC: Situated Design Cognition

TRIZ: Teoriya Resheniya Izobretatelshkikh Zadatch (Russian for 'Theory of Inventive Problem Solving')

UP: University of Pretoria 